\title{
CARLOS GARDEL, EL PATRIMONIO QUE SONRIE
}

\author{
María Julia Carozzi \\ Universidad Católica Argentina - Argentina
}

Resumen: Analizando los modos en que los porteños recordaron a Carlos Gardel en el mes del 68 aniversario de su muerte, el artículo intenta dar cuenta de una de las formas en que los habitantes de la ciudad de Buenos Aires conciben aquello que es memorable, identifican aquello en que se reconocen como porteños y singularizan aquello frente a lo cual experimentan sentimientos de pertenencia colectiva. El trabajo señala la centralidad que el milagro, la mimesis y el contacto directo con su cuerpo desempeñan en la preservación de la memoria de Gardel, quien encarna tanto al tango como a su éxito en el mundo. El caso de Gardel se presenta como un ejemplo de la organización de la memoria y la identidad de los porteños en particular y los argentinos en general en torno a personas reales a quienes se les asigna un valor extraordinario. Al sostener su profundo enraizamiento en cuerpos humanos concretos, tornan problemática la adopción local de los conceptos globalmente aceptados de patrimonio histórico y cultural.

Palabras clave: cuerpo, patrimonio, santos populares, tango.

Abstract: The article analyses one of the ways in which the inhabitants of Buenos Aires conceive that which is memorable, source of positive identification and origin of feelings of communitas by examining their commemoration of the $68^{\text {th }}$ anniversary of the death of Carlos Gardel. It underscores the central role that miracles, mimesis and direct bodily contact play in the preservation of the memory of the star, who incarnates both the tango and its world-wide success. The case of Gardel is presented as an example of the centrality that real persons of extraordinary value have in the organization of local memory and collective identity. Since they are embedded in concrete human bodies, they reveal problems in the local adoption of globally accepted concepts of historical and cultural heritage.

Keywords: body, heritage, popular saints, tango. 
Cuando hablamos de patrimonio, habitualmente pensamos en ruinas, iglesias, monumentos, barrios históricos, esculturas, pinturas conservadas en museos y objetos arqueológicos, reliquias materiales de un pasado que se vuelve, en ellos, tangible. Recientemente, un organismo internacional, la UNESCO introdujo otro concepto, el de "patrimonio intangible", que fue luego incorporado por otros organismos y por gobiernos nacionales y locales. Este concepto, según fue definido por Lyndell Prott en un informe de la organización, designa el "conocimiento cuyo uso se transmite de una generación a otra, obras literarias y artísticas que pueden ser creadas en el futuro, música, danza, cantos, ceremonias, símbolos, diseños, narrativas y poesía; todo tipo de conocimiento científico, agrícola, técnico, ecológico, incluyendo el uso racional de la flora" (apud Ochoa Gautier, 2001, p. 11).

$\mathrm{La}$ (im-)posibilidad de distinguir entre patrimonio tangible e intangible dio lugar a un gran número de discusiones por parte de sociólogos, folklorólogos y antropólogos culturales y sociales que han comenzado a actuar como funcionarios, expertos y consultores gubernamentales a partir de esta introducción de lo intangible al patrimonio (Comisión para la Preservación del Patrimonio Histórico Cultural de la Ciudad de Buenos Aires, 2001, p. 3) ${ }^{1}$. En relación con esta dimensión de intangibilidad, es interesante la forma en que Jordi Tresserras (2001) relató en Buenos Aires, el origen del reconocimiento por parte de la UNESCO del patrimonio intangible y el inicio del programa de Tesoros Humanos Vivos. De acuerdo con su relato, el gobierno de Marruecos propuso patrimonializar a unos contadores de cuentos que se reunían en la plaza de Jeema'. La propuesta de Marruecos se refería no a la plaza, como hubiera sido esperable hasta el momento, sino a los contadores de cuentos. La presentación originó una serie de discusiones en la UNESCO debido probablemente al hecho de que, para sus funcionarios, los contadores de cuentos no eran lo suficientemente tangibles como para ser patrimonializados. Como resultado del debate, se pronunció la declaración del organismo en relación con las "obras maestras de la humanidad en relación al patrimonio oral y al intangible" (Tresserras, 2001, p.194). También se estableció un programa que es el de Tesoros Humanos Vivos con el propósito de promover la transmisión de las destrezas y técnicas tradicionales por los artistas y artesanos, antes de su desaparición

Hasta entonces, los expertos convocados eran principalmente arquitectos e historiadores y secundariamente arqueólogos.

Horizontes Antropológicos, Porto Alegre, ano 9, n. 20, p. 59-82, outubro de 2003 
por causa de abandono o falta de reconocimiento. Lo que, desde entonces, ambos programas se dirigen a preservar es a las destrezas y no a los artistas y artesanos: si alguien es declarado "Tesoro Humano Vivo" en razón de su habilidad descollante en una disciplina patrimonializada, debe comprometerse a transmitir su saber. En tanto, si deja de enseñar su habilidad, pierde su cualidad de atesorable y el subsidio al que se había hecho acreedor. No se intenta, en suma, preservar a los "tesoros humanos vivos" por lo que son, ni por lo que hacen o ejecutan, sino en tanto transmisores de un saber que se define como valioso.

De acuerdo con el relato de Tresserras (2001), lo que originalmente el gobierno de Marruecos pretendía patrimonializar era a las personas de los contadores de cuentos, esto es, pretendía proteger, conservar y promocionar a los contadores de cuentos: no a los cuentos, ni al evento en que contaban sus cuentos, ni a las acciones o el saber que ellos implicaban. El hecho de que este intento haya producido nuevos programas de la UNESCO revela la imposibilidad de sus funcionarios de concebir como objeto de protección, preservación y promoción a personas que, como los monumentos que se patrimonializan, tienen un valor incorporado e inseparable de su materialidad. En cambio, resultó concebible patrimonializar los cuentos transmitidos oralmente y posibilitar que se patrimonializaran después los mitos, las ceremonias y los rituales. En contraste con la propuesta original de Marruecos, la declaración de la UNESCO parece el resultado de la reificación de algunos principios explicativos y recortes usuales de los saberes globales académicos, como los géneros discursivos, las tramas de significados, las operaciones y las performances, reificación que se realiza a condición de su separación de los cuerpos humanos que los encarnan. Al mismo tiempo, la introducción de obras artísticas, ceremonias, diseños, narrativas y poesía, conocimiento agrícola, técnico y ecológico al concepto de patrimonio resuena con transformaciones en lo que tiene valor de cambio en el mercado internacional. Como señalara Yúdice (2001), el combustible que impulsa la acumulación económica en la etapa postindustrial del capitalismo global es, como el nuevo patrimonio, también de carácter intangible. La declaración de la intangibilidad del patrimonio enmarca, entonces, lo memorable y preservable como conocimiento transmisible. Sólo a condición de separar tanto las obras del espíritu humano como las habilidades que las mismas suponen de los cuerpos de las personas que los producen puede un mito, una leyenda, un ritual o una ceremonia, ser considerada intangible. 
El relato de Tresserras resulta relevante para el contexto porteño y argentino porque lo que Marruecos con los contadores de cuentos propuso originalmente parece aproximarse más a algunas de nuestras políticas populares en términos de memoria y preservación, que la posición que prevaleció en la UNESCO posteriormente cuando admitió la patrimonialización de lo intangible ${ }^{2}$. Las Terceras Jornadas de Patrimonio Intangible (en prensa) convocadas por el Gobierno de la Ciudad de Buenos Aires, tuvieron como título "El lugar de los mitos rituales y celebraciones en el patrimonio cultural" $\mathrm{y}$, por primera vez, convocaron especialmente a cientistas sociales que investigan en el área de la religión. Uno de los rasgos distintivos de esas jornadas fue la gran cantidad de ponencias presentadas sobre ídolos locales y difuntos milagrosos. Este sesgo temático de los cientistas sociales porteños $^{3}$ en relación a lo que la UNESCO entiende como patrimonio intangible constituye, a mi entender, una clave acerca de uno de los modos diferenciados en que los habitantes de Buenos Aires entienden lo que es su patrimonio. Es decir, conciben aquello que es memorable, identifican aquello en lo que se reconocen como porteños y singularizan aquello frente a lo cual experimentan sentimientos de pertenencia colectiva. El desvío de lo memorable y lo sagrado hacia personas concretas, vivas y muertas, problematiza justamente la supuesta intangibilidad de lo patrimonializable, ya no en relación a la tangibilidad de la cultura material, sino en relación a los cuerpos humanos que lo encarnan. Los porteños parecen insistir en reconocerse y unirse en relación a personas extraordinarias que conceptualizan como inseparables de las acciones y las obras que produjeron.

Producto probablemente de la apropiación y reelaboración popular de una evangelización basada en santos y santos patronos, y de una posterior inmigración masiva de italianos y españoles pobres, desde el Gauchito Gil al conjunto de los desaparecidos de la última dictadura, pasando por el Che Guevara; desde la Madre María a Evita, y desde Gardel a Maradona, una buena parte de lo que nuestra memoria local preserva y una buena parte de

\footnotetext{
2 Resulta necesario subrayar que me refiero sólo a algunas políticas populares porque las políticas de patrimonialización populares en una ciudad con el grado de heterogeneidad original, inmigración interna, limítrofe y extranjera que ha tenido y tiene Buenos Aires, son muy variadas.

3 A lo largo de este trabajo "porteños" designa a los habitantes de la ciudad de Buenos Aires.
}

Horizontes Antropológicos, Porto Alegre, ano 9, n. 20, p. 59-82, outubro de 2003 
lo que convoca a amplios sectores de la población, se organiza en torno a personas reales a quienes se les asigna un valor extraordinario. Personas que consideramos únicas e irrepetibles, y de las cuales ninguna de las muchas escenas que componen sus siempre discutidas, siempre crecientes y siempre dialogadas mitografías (Martín, A., en prensa), supone que aprendieron algo de alguien o podían enseñar algo a alguien. Personas, en suma, con las que es posible identificarse - a veces a condición de reformar, cortar o ampliar sus vidas - de las que es posible recibir desde favores a alegrías, a las que es posible imitar una vez muertas y cuyo contacto directo es considerado siempre numinoso. Personas cuyas acciones y cualidades extraordinarias son inseparables de sus cuerpos.

Me voy a detener aquí en el caso de Carlos Gardel porque, al mismo tiempo, goza de cierta sacralidad entre los porteños, en cuyo lenguaje cotidiano ser excelente en cualquier especialidad es "ser Gardel"; es junto con la Madre María ${ }^{4}$ uno de los dos difuntos milagrosos más famosos entre los visitantes habituales del cementerio del Oeste de la Ciudad de Buenos Aires $^{5}$ (probablemente seguido por otra cantante muerta en gira, Gilda); convoca a los fanáticos gardelianos, y, finalmente, el Gobierno de la Ciudad lo ha incluído en acciones de promoción del barrio del Abasto encuadradas en su declaración del tango como patrimonio cultural intangible de la ciudad de Buenos Aires ${ }^{6}$.

\section{El alma en el cuerpo}

Cementerio del Oeste (más conocido como La Chacarita). 24 de Junio de 2003. $68^{\circ}$ Aniversario de la muerte de Gardel. Hay unas ciento cincuenta personas alrededor de la bóveda donde yace junto a su madre, Berthe Gardés.. Entre ellos muchos hombres de entre 60 y 70 años, su tez clara revela que son descendientes de inmigrantes, su ropa, que pertenecen a las clases medias Hay más hombres que mujeres. Miembros de la Asociación Amigos de Carlos Gardel organizan la entrada de los visitantes a la cripta. Uno de ellos comenta

\footnotetext{
4 María Salomé Loredo de Subiza, sanadora discípula de Pancho Sierra, fallecida en 1928.

5 Este cementerio es conocido popularmente como "cementerio de la Chacarita".

${ }^{6}$ Ley número 130 sancionada el 14 de diciembre de 1998.
} 
que hace poco visitó a Ceferino (Namuncurá), de quien se dice fue compañero de colegio de Gardel.. "Yo creo que la muerte de Ceferino fue por negligencia. Los Salesianos hablan mucho, pero quién sabe cómo lo trataban". Parada junto a mí frente a la estatua que se yergue en un promontorio al lado de la cripta, una mujer me dice: "Usted tiene que bajar a verlo, este año abrieron la puerta. El de arriba es él, abajo está la madre". Otro señor, se agrega a un grupo cercano de hombres: "Fui a ver a mi mujer y a mi tío, están todos allá abajo" [se refiere a los nichos colocados en corredores subterráneos].

Hago la fila para entrar a la bóveda. Detrás de mí un señor comenta que, aunque viene todos los años, es la primera vez que tiene oportunidad de ver a Gardel, ya que las autoridades del cementerio nunca abren la puerta. Otro hombre desmiente la versión, afirmando que él sí lo vio una vez. "Tuvo suerte", le responde un tercero, "yo también vengo siempre y nunca lo vi". Bajamos a la cripta de a cuatro. Una vez frente a los dos ataúdes mis ocasionales compañeros preguntan cuál de los dos es el de Gardel. El gardeliano que cuida la puerta les responde: "el de arriba, el de abajo es el de la madre" Dos de mis acompañantes -un hombre y una mujer- colocan la mano sobre el cajón, el otro acerca su mano sin llegar a tocarlo. Con su mano sobre el féretro, la mujer le habla luego a Gardel en voz alta: "Ayúdanos a todos los argentinos, que tanto hemos sufrido, ayúdanos a salir adelante!" (Cuaderno de campo).

Como atestiguan algunas de las placas de agradecimiento colocadas sobre y alrededor de su bóveda en el cementerio de la Chacarita, Gardel ha venido concediendo favores a los vivos hasta la actualidad. En razón de esta cualidad, Gardel se aproxima a otros difuntos milagrosos a lo largo del territorio argentino en general y del cementerio del Oeste en particular. Algunos de quienes le piden ayuda visitan no sólo su tumba sino también la de la Madre María, manosanta contemporánea de Gardel, en un recorrido que asimismo incluye como estaciones los nichos donde se encuentran otros muertos amados, a quienes a menudo también se les pide ayuda en los problemas de la vida. En estos recorridos Gardel y la Madre María quedan asociados a una comunidad de difuntos cercanos que tienen capacidad de protección sobre los vivos. 
Muchas personas se refieren al recorrido de este circuito diciendo que "van a ver" o "van a visitar" a su esposa, a su madre, a Gardel y a la Madre María. En estos últimos casos a cambio de los favores recibidos, depositan flores cerca de donde se hallan sus cuerpos. El cuerpo muerto no es, para estos promesantes, considerado un desperdicio: el difunto se halla de algún modo presente allí donde se halla el cuerpo y la muerte no elimina la condición del cuerpo como lugar donde la persona se encuentra. Con poco tacto, una antropóloga francesa que vivió muchos años en Buenos Aires, se refiere a las prácticas que expresan este enraizamiento del alma en los cuerpos como "manifestaciones necrofílicas":

Los funerales de Encarnación Ezcurra fueron grandiosos. Rosas ordenó que se le rindieran los honores de capitán general, y se decretó un duelo de dos años. Al ver pasar la carroza fúnebre de la esposa del "Restaurador", centenares de mujeres se enfermaron. Estas manifestaciones necrofílicas ligadas al poder político, cuyo secreto posee Buenos Aires, debían reproducirse durante las defunciones de Hipólito Yrigoyen, Carlos Gardel [y] Eva Perón [...]. Ochenta años después de su muerte, el cuerpo de la heroína fue exhumado y transportado al cementerio de la Recoleta, en el panteón familiar de los Ortiz de Rozas. Se comprobó que su cadáver no había sido corrompido y que los rasgos de su rostro habían quedado fijados desde la noche de su muerte: se admiró su pelo castaño peinado en bandas, la boca entreabierta como si recitara una oración y los ojos "cerrados pero intensos, como si estuvieran vivos". Su pariente, monseñor Marcos Ezcurra, vio en esto la marca del designio de Dios. (Bernard, 1999, p. 158).

En el intercambio de pedidos, promesas y agradecimientos de los visitantes del cementerio de "la Chacarita" que creen en milagros, las reliquias se unen al altar, una unión que los historiadores del cuerpo religioso tienden a confinar al medioevo europeo (Le Goff, 2002; Mellor; Shilling, 1997; Rodrigues, 1999). Tanto en relación con Gardel como con la Madre María los visitantes del cementerio dicen que "es una suerte" cuando los guardias deciden abrir las puertas de sus bóvedas y pueden acercarse más a ellos. En esas ocasiones los devotos acercan o apoyan sus manos sobre los féretros mientras conversan, piden y agradecen a sus difuntos. Cuando las 
puertas están cerradas apoyan sus manos sobre ellas o sobre el mármol de las paredes. Es entonces, la de estos visitantes del cementerio, una sensibilidad para la que el contacto directo con el cuerpo milagroso supone una comunicación más fuerte que la mera contemplación de la imagen o la palabra pronunciada a la distancia. El tacto posibilitado por la co-presencia se erige como el sentido privilegiado de la relación religiosa y cuando es posible permite una comunicación más valiosa que la vista o el oído por sí solos. En ello, esta sensibilidad se diferencia tanto de la sensibilidad religiosa que se supone propia del protestantismo de la reforma, que prioriza la palabra leída o escuchada, como la que se atribuye al catolicismo de la contrarreforma, que prioriza la contemplación de imágenes como medios de suscitar experiencias religiosas (Mellor; Shilling, 1997).

Difuntos modernos y famosos, sin embargo, tanto junto a la bóveda de Gardel como junto a la de la Madre María hay estatuas de bronce que reproducen sus cuerpos vivos. La del primero además, como casi todas las fotos de Gardel, sonríe.

Cementerio del Oeste. 24 de junio de 2003. Un miembro de la Asociación Gardeliana y una niña que parece su nieta, parados junto a la estatua de Gardel, ordenan las flores que traen los visitantes que van llegando y prenden los cigarrillos que colocarán uno tras otro, en su mano derecha. Han colmado de flores el espacio entre el brazo izquierdo de la estatua y su cuerpo. Abundan los claveles rojos.También han colocado un escudito de Racing ${ }^{7}$ en la solapa del cantor. Un hombre canta emocionado, con una flor blanca en la mano, mirando a los ojos a esa estatua sonriente, que es Gardel frente a su canto. A dos cuadras, la estatua de la Madre María con los brazos colmados de flores mantiene diariamente un destino similar. (Cuaderno de campo).

Con el escudo, los cigarrillos y las flores la estatua se humaniza, ese ajuar efímero que se consume en horas o en días, la vivifica. Algunos gardelianos se refieren al poder mimético (Taussig, 1993) de esta estatua llamando a Gardel "el bronce que sonríe". La exactitud de la reproducción en relación con la imagen de las fotos de Gardel no es un detalle menor.

${ }^{7}$ Club deportivo con cuyo equipo de fútbol, se dice, Gardel simpatizaba (Groppo, 2003).

Horizontes Antropológicos, Porto Alegre, ano 9, n. 20, p. 59-82, outubro de 2003 
Cuando el Gobierno de la Ciudad emplazó otra estatua en la esquina en que se encontraba el antiguo bar Chanta Cuatro, convertido ahora en un lujoso reducto turístico que se anuncia como "La Esquina Carlos Gardel", frente al lugar donde se encontraba el Mercado de Abasto ahora transmutado en shopping, muchas quejas se alzaron diciendo que el hombre representado en la estatua no "era" Gardel, porque era demasiado flaco. Ignorando los principios de la participación simpática, el locutor que anima el espectáculo de tango que el Gobierno de la Ciudad organiza el mismo 24 de junio junto a ella, dirá: "Dicen que no se parece a Gardel, qué es muy flaco. Qué importa que sea flaco, lo importante es que aquí haya una estatua de Gardel y no una de los Rolling Stones".

La cercanía de la estatua con el cuerpo yacente de Gardel, tampoco es indiferente a su identidad con él, no hay flores en la estatua recientemente emplazada en el barrio del Abasto, y nadie canta mirándola a la cara, ni siquiera el 24 de junio. Hay en cambio, junto a ella una placa de bronce con una foto, recordando al recientemente fallecido historiador inglés Simon Collier, "gardeliano", "piazzoliano" y autor de una de las biografías más recientes de Gardel. Investigar y escribir sobre la vida del "Morocho del Abasto" y ser miembro de dos de las instituciones que promovieron el emplazamiento de la estatua parece haberle contagiado parte de la sacralidad del ídolo.

La muerte trágica y lejos del hogar de Gardel lo asemeja a la mayor parte de los difuntos milagrosos del territorio nacional (Chertudi; Newbery, 1978). La reconstrucción de su biografía que se opera inmediatamente después de su muerte y que los Gardelianos más afectos a la investigación de la historia escrita hoy desechan como falsos, lo acercan aún más a estos difuntos. Esas tempranas reconstrucciones biográficas, de las que da cuenta Collier (1988, p. 26) como conformando "la leyenda de Gardel", parecen revelar la existencia de unas escenas comunes ligadas a algunas santificaciones populares.

Sobre el único hecho histórico comprobable de que el avión en que Gardel partiría desde Medellín el 24 de junio de 1935 para continuar una gira artística, perdió su dirección, chocó con otro y se incendió, parecen haberse producido entre los gardelianos variaciones que apuntan a reforzar sus

\footnotetext{
8 "El Morocho del Abasto" es una de las denominaciones con que los porteños se refieren a Gardel.
} 
similitudes con otros difuntos milagrosos. Algunas versiones sugirieron que el choque del avión se produjo debido a un tiroteo entre Gardel y el piloto, quien era además el dueño de la compañía aérea (Collier, 1988). Las semejanzas se ven reforzadas por las también discutidas escenas que ponen a Gardel en su juventud en conflicto con la ley. Una de ellas lo imagina confinado durante un año en la cárcel de Usuahia, según algunas versiones por tener amoríos con la mujer de un miembro poderoso de la aristocracia porteña. Otra, lo imagina expatriándose en Montevideo después de un violento altercado en la oficina de correos (Collier, 1988, p. 35). Aún en otra, recibe un balazo en el pulmón por salir en defensa de un amigo que había sido insultado por un sujeto adinerado en un baile en el Palais de Glace (Orgambide, 2003). Estas escenas reconstruyen la biografía gardeliana asemejándola a las atribuidas a la vida y la muerte de los muchos jinetes rebeldes, gauchos alzados y bandoleros románticos que se tornaron milagrosos en Argentina después de vivir en conflicto con la ley y morir en manos de uniformados, generalmente la milicia o la policía (Carozzi, en prensa; Chumbita, 2000)9 .

Las escenas creativamente recordadas por quienes hablaron y escribieron sobre Gardel inmediatamente después de su muerte tendrán más tarde en la historia versiones que las desmienten e incluso remiten a significados opuestos ${ }^{10}$. Sin embargo, los vínculos que establecen con otros difuntos milagrosos ponen de manifiesto el lugar central que el "poner el cuerpo" - y no la palabra - jugándose la vida o soportando el dolor físico que ello supone, adquiere en la_santificación de los difuntos milagrosos en el territorio argentino.

En el caso de las difuntas milagrosas mujeres, el haber sufrido una violación real o supuesta previa a su muerte, o el haber sido descuartizadas después de ella, está a menudo en el origen de su capacidad de obrar milagros, constituyendo ellas entonces la contracara pasiva y sexualizada de la misma centralidad del cuerpo sufriente en la santificación. Podemos

\footnotetext{
9 Como era de esperar, esta reconstrucción biográfica también tiene su personificación. Gardelito, así llamado por un parecido con Gardel que él cultivaba en su peinado y su ropa, jefe de la banda "los Gardelitos" especializada en el "duqueo" (extraer billeteras de los bolsillos ajenos con dos dedos), que operaba en Buenos Aires y Tucumán, muerto en un enfrentamiento con una banda rival, también es milagroso para los visitantes del cementerio de esta última ciudad, donde se halla su bóveda.

10 Matamoro (1969) por ejemplo, describe un Gardel cantor de comité, y destaca como rasgo distintivo su estrecha relación con los políticos conservadores.
}

Horizontes Antropológicos, Porto Alegre, ano 9, n. 20, p. 59-82, outubro de 2003 
adivinar en este sufrimiento físico relacionado tan a menudo con la capacidad de obrar milagros, una reelaboración moderna y popular de una evangelización basada en imágenes de santos barrocos cuya característica visible eran la herida y el sufrimiento (Jáuregui, 1999).

Las numerosas escenas que describen a Gardel como extraordinariamente generoso y ayudando a todos aquellos necesitados que se le acercaban pidiendo dinero o ayuda (Collier, 1988, p. 161) también acercan su mitografía a la de otros difuntos milagrosos, como su actual vecina la Madre María y Evita. El ocultamiento del cuerpo de esta última por parte de los militares que llevaron a cabo el golpe de estado que derrocó a Perón, y su actual emplazamiento en el aristocrático cementerio de la Recoleta, probablemente impidieron que sobre su tumba se construyera un altar de milagros ${ }^{11}$. El trabajo metódico de los militares argentinos para ocultar el cuerpo muerto y embalsamado de Evita atestigua que el cuerpo de los muertos en Argentina está lejos de ser considerado un desperdicio y, por el contrario, es objeto de una sacralización que mediante su escamoteo se pretende evitar ${ }^{12}$.

No todas las placas colocadas sobre la bóveda de Gardel agradecen milagros, ni todos quienes se congregan allí los 24 de junio o visitan en otros días al "bronce que sonríe" y dejan cigarrillos en su mano creen que Gardel pueda hacer otro prodigio que su pinta, su sonrisa y su particular modo de cantar.

En La Mesa del Café, un foro de Internet, donde intercambian mensajes varios tangueros, recientemente escribía Osvaldo:

\footnotetext{
11 Podría argumentarse que Evita no se hubiera convertido en difunta milagrosa por no haber sufrido una muerte violenta. Sin embargo, algunos sanadores bonaerenses como Pancho Sierra y la Madre María, son milagrosos aún cuando no hayan sufrido muertes violentas. Por otra parte, como atestiguan algunos de los santos populares consignados por Chertudi y Newbery (1978) en algunos casos el sufrimiento del cuerpo después de la muerte parece reemplazar a la muerte violenta como origen de la canonización popular.

12 Más lejos de Buenos Aires, Chumbita (2000) proporciona otro ejemplo del ocultamiento del cuerpo para evitar el milagro en el Chaco: las autoridades establecieron vigilancia en las tumbas de Machagai para impedir la sacralización del cuerpo muerto del "vengador" Isidro Velázquez, correntino que alcanzó fama de invencible y una de las últimas figuras del bandolerismo campesino muerto por la policía. Sin embargo periódicamente reaparecen flores y ofrendas en su sepulcro.

En la sacralidad otorgada al cuerpo del difunto, la sensibilidad religiosa de estos argentinos se diferencia de la que Calavia Sáez (1996) describe para Brasil, cuando afirma que, para ella, el cuerpo es desperdicio y lo único que importa es el alma.
}

Horizontes Antropológicos, Porto Alegre, ano 9, n. 20, p.59-82, outubro de 2003 
Buenas noches muchachos. Tal vez esta no es una noche cualquiera, pues no vengo babeando ni hablando solo, tampoco tengo la corbata floja y suelta y mucho menos, rencor al mirar. Les cuento que estuve en la Chacarita, y no fui allá porque sea un carro viejo, sólo quería hacerle una visita al Morocho, lo encontré sonriendo como siempre, me aceptó un cigarillo, estaba contento porque ya empezó la primavera con sus fulgidos colores. Luego visité a [Agustín] Magaldi, es costumbre suya, tener su guitarra lista para entonar su mejor canción y a su lado el Gordo de Oro [se refiere a Aníbal Troilo] haciéndole dúo con su bandoneón. (La Mesa del Café, setiembre 2002).

A estos Gardelianos que no creen en milagros me referiré a continuación.

\section{La mimesis y el contacto}

[Respuestas a una comparación entre Gardel y el cantor de tangos Edmundo Rivero]

El Ciruja: - Rivero: grande, muy grande. Gardel: inabarcable, infinito, genial, supremo, inigualable, inalcanzable, maestro creador,...y por supuesto fuera de toda comparación. No es que esté mal compararlos, es que simplemente es perder el tiempo.

Vicente: - Estoy de acuerdo con El Ciruja en que es una pérdida de tiempo lo de las comparaciones. Yo sólo puedo decir que cuando escucho a Gardel consigue transmitirme un sentimiento que no lo consiguen los otros (siendo buenos cantantes). Es como un poder mágico que sólo lo tiene él ¿Cuál es el misterio? Si alguíen sabe explicarlo le animo a que lo haga aquí en la mesa. (La Mesa del Café, Sección "Carlos Gardel”, junio 2003).

24 de junio de 2003, Acto de Homenaje del Gobierno de la Ciudad en el Abasto:

Daniel, que se ha dedicado a intentar seducir a buena parte de las mujeres presentes durante toda la tarde, me dice al oído:

- Si yo tuviera la cuarta parte de la pinta [apariencia atractiva, estampa] que tenía Gardel... Tenía todas las mujeres a sus pies, todas: viudas, casadas, solteras. Ninguna le decía que no. (Cuaderno de campo). 
No todos quienes mantienen vivo el recuerdo de Gardel creen que Gardel pueda operar milagros en las vidas de los otros. Hay un número de admiradores fanáticos de Gardel para quienes Gardel no hace milagros porque, como escribe El Apóstol en el foro, él "ya es un milagro" o tiene "como un poder mágico" para transmitir sentimientos del que carecen los demás cantores. Como todo porteño sabe, Gardel "cada día canta mejor", en esta ciudad ser excelente en cualquier especialidad es "ser Gardel" y, como dice el tango, en las esquinas de Buenos Aires "cualquier cacatúa sueña con la pinta de Carlos Gardel". De modo que hay una sacralidad (Martín, E., 2003) de Gardel que muchos porteños sostienen y que se intensifica entre los gardelianos más fanáticos.

Lo que desde quienes intercambian mensajes escritos en el foro dedicado a Gardel del sitio Todo Tango en Internet hasta los locutores de noticieros el 24 de junio recuerdan, son "su pinta", "su sonrisa eterna" y "su voz". No es la música de los tangos que Gardel compusiera, esa obra "del espíritu" (Lacarrieu; Pallini, 2001, p. 84) desincorporada, la que se recuerda con emoción y la que lo convierte en único e indiscutible, sino la letra y la música hechas cuerpo, los tangos cantados por Gardel, con la pinta de Gardel y la sonrisa de Gardel. A la persistencia en el tiempo del conjunto, contribuyeron seguramente mucho sus películas, que en Buenos Aires se siguen reponiendo en ciclos especiales hasta hoy, pero también el modo particular de apropiación de las mismas por parte de los espectadores porteños, quienes obligaban a los proyectoristas a rebobinarlas para volver a ver una y otra vez los tramos en que Gardel cantaba (Collier, 1988). Son esos fragmentos de películas los que aún hoy los noticieros de la televisión abierta en el aniversario de la muerte de Gardel y los canales de cable dedicados al tango y al recuerdo en cualquier momento del año, vuelven a reproducir (Carlini, 2003).

Cementerio del Oeste. 24 de junio de 2003. Dos grupos lo suficientemente alejados entre sí como para no superponer sus voces se reúnen alrededor de una guitarra y cantan los mismos temas que Gardel cantaba en sus películas, algunos de ellos visten traje oscuro, camisa clara, corbata o moño, pelo engominado peinado hacia atrás y sombrero de ala corta, como Gardel. (Cuaderno de campo).

Si no se puede imaginar a Gardel enseñando su modo de cantar, la estampa, la sonrisa y la modulación de la voz del Morocho del Abasto son 
en cambio asimiladas en el propio cuerpo de los fans/imitadores que lo personifican (Martín, A., en prensa). Es posible encontrarlos acompañados por guitarristas cantando por monedas en los barrios turísticos de Buenos Aires, como la Recoleta y San Telmo durante los fines de semana, y junto a su bóveda en los aniversarios de la muerte del ídolo. Para ellos, cantar como Gardel, implica imitar su modo de peinarse, hacia atrás a la gomina, vestir traje oscuro y lucir un sombrero similar al suyo. El canto de Gardel y la pinta de Gardel son para ellos un todo indisoluble y sólo pueden ser incorporados mediante la personificación.

Fuera del mundo del tango-canción, en el de tango-danza - que en raras ocasiones se superponen pero se suman en la entronización de la imagen de Gardel $^{13}$ - los bailarines suelen adoptar un estilo gardeliano de vestir y peinarse. Miguel Angel Soto, probablemente el bailarín profesional de tango más famoso de esta generación, incluye en su biografía pública el hecho de que un tío que se encontraba enfermo, al despertar una noche y verlo vestido de smoking y engominado para un espectáculo le preguntó “¿ya llegué?" Según cuenta el bailarín, su tío al verlo creyó que había muerto y llegado al cielo, encontrándose allí con Gardel.

Estas personificaciones de Gardel que lo reproducen en el cabello negro y engominado, el sombrero de ala corta, el traje oscuro o el frac y la corbata o el pañuelo de seda, lo emparentan en nuestro medio con apropiaciones similarmente miméticas (Bourdieu, 1991) del cantante cuartetero Rodrigo, y de la cantante de cumbia Gilda, por parte de sus fans. Ambos, como Gardel, hermosos para los cánones locales y muertos en accidentes durante giras ${ }^{14}$. Es posible que asemejándose a Gardel, los cantores de tango sientan que obtienen parte de su carisma personal, así como las mujeres del Gran Buenos Aires imitando a Evita y actuando como ella sienten que obtienen parte de su capacidad de liderazgo (Seman, 2000).

Si la mimesis constituye un modo de incorporar y reproducir el carisma de un ídolo, otro modo es sin duda el contacto directo con él. El contacto con un ídolo es siempre numinoso, se recuerda - a veces se inventa - y siempre se cuenta, ya sea de persona a persona o a través de medios de comunicación, de modo que las anécdotas que conforman las entradas de ese diálogo que conforma la biografía colectiva de Gardel son numerosísimas

13 Gardel casi nunca cantó con orquestas y sus tangos no son bailables, pero su imagen decora las paredes de varios salones de baile.

${ }^{14}$ Fuera de nuestro medio, el caso más documentado es probablemente el de los fans imitadores de Elvis Presley (Rodman, 1996). 
y se hallan ampliamente diseminadas en la población. El director del Museo "Casa Carlos Gardel" inaugurado este año por el gobierno de la Ciudad decía: "el Abasto debió ser, en época de Gardel, el barrio más poblado de Buenos Aires, porque todo el mundo lo conoció y todo el mundo tiene alguna anécdota que contar".

En el caso de Gardel, muerto hace ya sesenta y ocho años, y como comentaban los gardelianos reunidos en el 24 de junio en el Cementerio de La Chacarita, ya "quedan pocos" (vivos) de quienes gozaron de tal privilegio. Como demuestran los testimonios televisados en los programas especiales dedicados a la conmemoración de su muerte, lo que invariablemente recuerdan o imaginan recordar los demás son los contactos entre ídolos, a los que se les atribuye una particular sacralidad y un sentido, como si esos contactos presagiaran u originaran en los más jóvenes su calidad de seres excepcionales. Muchos suponen que el legendario payador Betinotti le prestó un día su guitarra al joven Gardel para que cantara y que en esa ocasión lo rebautizó como "El Zorzal Criollo" También se recuerda que Gardel fue compañero de colegio de Ceferino Namuncurá, el joven mapuche que los Salesianos impulsaran como beato y cuya imagen distribuyeron como santo local en Argentina. En otra escena la Madre María le habría impuesto las manos a Gardel curándolo de una enfermedad en la garganta. También es legendario el encuentro entre Aníbal Troilo, que sería sin duda el bandoneonista más destacado de la época de oro del tango bailado y Gardel cuando el primero era joven. Para muchos fue un presagio que Astor Piazzola conociera a Gardel en New York cuando niño, y que este último lo invitara a participar en una de sus películas y a acompañarlo en la gira donde finalmente moriría, destino del que el bandoneonista se salvó porque sus padres no lo autorizaron a viajar. Finalmente, a pocos les parece casual que el cantante de cuarteto que más éxito mediático tuvo en Buenos Aires, muriera en un accidente un 24 de junio, el mismo día en que murió Gardel. Los porteños adivinamos que en esos contactos y coincidencias o bien se manifiesta un común destino de excepcionalidad o bien se traspasa la cualidad de ídolo indiscutido de una época (Carlini, 2003).

\section{La encarnación del tango}

Cementerio del Oeste. 24 de junio de 2003. Cuando se aproxima la hora de la muerte de Gardel, ocurrida a las 15.10, el grupo de cantores ubicado más cerca de la bóveda entona "Silencio", el mismo tango 
que la orquesta de Canaro ejecutó en el velorio de Gardel, en el Luna Park, el día en que el cuerpo volvió a Buenos Aires desde Medellín, en 1936. Un hombre de gruesos anteojos y vestido de traje se para junto a la estatua/Gardel y pide un minuto de silencio, recordando que a esa hora murieron Carlos Gardel y sus amigos, y mencionando también a los muchos gardelianos que los acompañaban otros años y que ya no están. La pequeña multitud hace silencio y el señor que arreglaba las flores controla el tiempo. Cuando pasó un minuto exacto, el Gardeliano de anteojos parado junto a la estatua vuelve a hablar pero su voz es silenciada por uno de los cantores que, desde el grupo, comienza a entonar "Mi Buenos Aires Querido", tango que todos vimos cantar a Gardel en un fragmento de la película Cuesta Abajo mientras regresaba a Buenos Aires en la cubierta de un barco. Muchos de los presentes lo acompañan a coro: "mi Buenos Aires querido cuando yo te vuelva a ver no habrá más pena ni olvido"... y algunos versos más tarde "mi Buenos Aires, tierra florida, donde mi vida terminaré"... "quiero de nuevo yo volver a contemplar, aquellos ojos que acarician al mirar". Cuando el tango termina muchos de los presentes, incluídos los dos que filman el evento, tienen lágrimas en los ojos. (Cuaderno de campo).

Todos los años, cuando se acerca el 24 de junio, algún canal de televisión, reproduce ese pedacito de película en que Gardel canta Mi Buenos Aires Querido en la cubierta de un barco. La nostalgia por Buenos Aires y el deseo de volver, es un tema recurrente en las letras de Le Pera que Gardel musicalizaba y cantaba en la pantalla. En El Día que me Quieras, filmada en 1935, interpretaría Volver, que también trata del retorno a la ciudad, aunque aquí el sentimiento es más ambiguo y el cantor expresa temor por el reencuentro con un pasado doloroso. Los gardelianos prefieren hoy emocionarse al recordar cantando a aquel Gardel que deseaba volver a su querido Buenos Aires y no pudo completar su deseo sino después de muerto.

Buenos Aires es para esos tangos filmados como para otros tangos grabados por Gardel en Europa, una ciudad lejana. Así Enrique Cadícamo escribió la letra de "Anclao en Paris" en Barcelona y la envió a Carlos Gardel que estaba en esa ciudad donde éste la grabó en 1931, con música de Guillermo Barbieri. La letra, que en una de sus estrofas dice: "Lejano Buenos Aires, que lindo que has de estar, ya van para diez años que me viste 
zarpar. Aquí en este Montmartre, faubourg sentimental, yo siento que el recuerdo me clava su puñal", termina expresando miedo a morir lejos de la ciudad: "quien sabe algún día me encane la muerte y... chau Buenos Aires no te vuelva a ver". En 1933, grabó La Canción de Buenos Aires con letra de Manuel Romero que comienza "Buenos Aires, cuando lejos me vi sólo hallaba consuelo en las notas de un tango dulzón que lloraba el bandoneón..." y termina "y le pido a mi destino el favor, de que al fin de mi vida, oiga el llorar del bandoneón entonando tu nostálgica canción”.

Con sus numerosas giras, Gardel encarna al tiempo que canta la nostalgia por Buenos Aires, y el deseo de volver a ella, una nostalgia que alcanza en él su punto más eminente porque de hecho muere lejos de esta ciudad. Encarna también una forma particular de ser porteño que consiste en irse llevando a la ciudad en el sentimiento, ampliación transnacional de otro trayecto tanguero: irse del barrio al centro llevando al primero en el corazón.. El recordado "Nocturno a Mi Barrio" recitado de Troilo sobre la música de su bandonéon, lo expresa poéticamente: "Dicen que yo me fui de mi barrio: pero cuándo, cuándo si siempre estoy llegando".

Parafraseando a Archetti (2001), quien lo predica de Maradona, Gardel tuvo como cantante una vida diaspórica y transnacional, pero nunca dejó el barrio porteño del Abasto que lo vio crecer. Para los descendientes de inmigrantes europeos que habitan esta ciudad y que vivieron su juventud antes de la década del 60, para ser porteño no es necesario haber nacido en Buenos Aires, sino llevar a Buenos Aires en el corazón. Y cantar tangos es llevarla en grado sumo. Tal vez en parte por eso a diferencia de los uruguayos, que construyeron una leyenda del origen uruguayo de Gardel, los gardelianos porteños no construyen una leyenda de un Gardel argentino ${ }^{15}$, basta que haya cantado con sentimiento tangos que proclaman a Buenos

\footnotetext{
15 Durante toda su vida Gardel empleó un pasaporte uruguayo según el cual había nacido en Tacuarembó. Recién después de muerto su apoderado, Armando Defino hizo conocer su testamento, donde decía que había nacido en Toulouse bajo el nombre de Charles Romuald Gardés, y que declaraba a su madre Berthe Gardés heredera universal de sus bienes. Hoy los porteños adhieren casi universalmente a la verdad de esta historia póstuma mientras muchos uruguayos se aferran a otra. La tesis uruguaya supone que Berthe Gardés no era la madre de Carlos Gardel, sino que éste era uno de los muchos hijos naturales de un Coronel uruguayo apellidado Escayola y su cuñada, nacido en forma oculta en una estancia en Tacuarembó y entregado a Doña Berta para que lo cuidara. Al mismo tiempo esta tesis sostiene que la partida de nacimiento encontrada en Toulouse de Charles Romuald Gardés sí pertenece a un hijo de Berthe Gardés pero que éste no es el mismo Carlos Gardel que se hizo famoso, sino otro.
} 
Aires como la ciudad amada y añorada, y al propio tango como la canción porteña para que "el Mudo" adquiera identidad ciudadana.

En junio de 1935, cuando se conoció en Buenos Aires la noticia de la muerte de Gardel muchas personas afirmaron que Gardel era "el tango hecho carne", mientras un discurso pronunciado en su velorio porteño del Luna Park afirmaría: "no hemos perdido a un cantor sino a la canción misma" (apud Collier, 1988, p. 333).

El propio Gardel, con una cuidadosa selección de lo que divulgaba y lo que mantenía secreto de su vida ${ }^{16}$ parece haber reconstruido su biografía pública para acercarla a las historias narradas en los tangos. Hoy los Gardelianos conectados a Internet reactualizan esta imagen recordando al propio Gardel definiéndose en reportajes como personificación del tango:

Jack: Carlos Gardel en una entrevista para el Diario Noticias Gráficas, del 21 de septiembre de 1933:

“- [...] sé que soy el tango cuando al salir del hipódromo me siguen con la vista los muchachos de la popular; no me engaño cuando el sastre se esmera por hacerme su mejor traje o la vendedora me busca entre todas, la corbata más linda. Sé que el homenaje es al tango. Yo soy para ellos el tango. Y me gusta, porque así soy más criollo. Aún cuando entono una dulce canción francesa, aún cuando la gente me escucha las bellas notas de Parlez Moi d'Amour, yo sé que soy el cantor de tangos que se presta para otras canciones."

Roberto: Muchas Gracias Jack por reproducir aquí estas palabras de Gardel, que nos lo descubren por sí mismo, en su propia voz. También decía que: "No soy yo el que triunfa, es el tango". (La Mesa del Café, Sección "Carlos Gardel”, junio 2003).

Muchas de las anécdotas de la vida de Gardel que estos gardelianos incansables coleccionistas de historias, reportajes y documentos que iluminan los misterios de la vida del "Troesma"17 - comparten en el Foro, contribuyen a construirlo como personificación de las letras de los tangos que él mismo

\footnotetext{
16 Por ejemplo, no reveló que había nacido en Toulouse, Francia, hasta que se conoció su testamento una vez fallecido. También mantuvo cuidadosamente oculto su prolongado noviazgo y su convivencia con Isabel Martinez del Valle, así como probablemente otros romances (Aballe, 2003).

17 Maestro al "vesre" (revés) es otra de las denominaciones porteñas de Gardel.
} 
cantaba. Rememoran su gusto por las carreras de caballos, sus entrañables recuerdos del barrio del Abasto en cuyas calles y bares se hizo hombre y cantor, su fidelidad a los amigos de su juventud $\mathrm{y}$, sobre todo, el amor incondicional por su madre como el más significativo y profundo de todos ${ }^{18}$. Colaborando en construir con sus recuerdos una vida que expresa estos temas centrales en las letras del tango canción - el hipódromo, el barrio, los amigos y el amor a la madre (Archetti, 1994) - continúan actualizando hoy su condición de encarnación del tango. Para estos Gardelianos, como para muchos porteños descendientes de inmigrantes que vivieron su juventud antes de la década del 50, el tango describe al hombre de Buenos Aires, de modo que a un tiempo que encarna a las letras del tango en su vida, Gardel personifica la identidad ciudadana.

Ángel: El último rasgo típico del hombre porteño, que Gardel encarna perfectamente, es el que se relaciona con la actitud hacia la madre [...] En las mencionadas declaraciones a Mario Dillon, Gardel encara el tema con palabras que parecen arrancadas de la letra de uno de sus tangos...Dice Gardel en el mencionado reportaje de 1930: 'Cuando necesito de paz, de tranquilidad, de sosiego...cuando muchos copetines y muchas farras me han cansado, vengo a ver a mi viejita y a su lado recobro fuerzas... Y es que en Buenos Aires, che, las cosas son duras para un tipo que sabe que la vida es corta y que un día perdido no vuelve más...Y aparte de todo eso ¡qué amigos, ni amores, ni gloria, ni triunfos, ni burros, ni nada por el estilo, al lado de una madre!El más modesto pucherete hecho por sus manos vale más y es más sabroso que el más caro de los platos del mejor de los hoteles del mundo. Son muy agradables los aplausos del público, pero ¿de qué valen al lado de un "has cantado muy bien", de la viejecita?'. Coco: Por todo lo que volcaste en tu nota, es que nosotros queremos a ese Gardel, que es bien nuestro, sin fronteras y sin paternidades. Ese Gardel nuestro, que nos nació en el Abasto!!! (La Mesa del Café, Sección “Carlos Gardel”, junio 2003).

\footnotetext{
18 Este amor incondicional está expresado una y otra vez en la letra de muchos tangos como Flor de Fango, Margot, Madre, Nunca es Tarde, Milonguera y La Casita de Mis Viejos Para estos tangos, contemporáneos de la vida de Gardel "la madre idealizada es la fuente de amor incondicional y abnegación absoluta" (Archetti, 1994, p. 112).
} 
Los Gardelianos que escriben y publican libros, no escapan de esta imagen de Gardel como personificación del tango. Tanto Gobello (1997) como Collins (1988) ven en el regreso de Gardel ya muerto a Buenos Aires la encarnación de Golondrinas, tango que "el Morocho" estrenara en la película El Tango en Broadway (filmada en Long Island en 1934). Dice el primero:

Un año después de haber filmado El Tango en Broadway, película en la que había estrenado "Golondrinas", Carlos Gardel moría trágicamente en Medellín, el 24 de junio de 1935, en un accidente aéreo. Ocho meses después, el miércoles 5 de febrero de 1936, el vapor "Panamerican" regresaba a Buenos Aires los restos mortales del cantor. Treinta mil personas vieron bajar el ataúd cubierto de flores, sostenido por el cable de una grúa. Pareciera como que se hubiese cumplido una oculta premonición escondida en las letras de aquel tango: "...con las alas plegadas también yo he de volver..." (Gobello, 1997, p. 212)

\section{El patrimonio inmortal}

Cementerio del Oeste. 24 de junio de 2003. En la mano izquierda de esa estatua que hoy es Gardel, hay una banderita de Cuba. A sus pies, en un cartel que agradece a Gardel por su arte, se lee claramente "Mexico". Estos adornos efímeros resaltan una internacionalidad que ya se halla expresada en las leyendas de las menos visibles pero más permanentes placas de bronce colocadas sobre las paredes externas de la bóveda que expresan el recuerdo afectuoso de gardelianos de Uruguay, Brasil, Chile, Perú, Bolivia, Ecuador, Cuba, Colombia, República Dominicana, Venezuela, Alemania, Francia, España, Japón, y los Estados Unidos. (Cuaderno de campo).

Este año el Gobierno de la Ciudad transformó en museo la casa del Abasto que Gardel, demostrando su tanguera fidelidad al barrio "que lo vio crecer", comprara ya famoso y viviendo la mayor parte del tiempo lejos de Buenos Aires. En el salón principal del museo, que casi no guarda objetos personales del "Troesma Inmortal" porque los coleccionistas no acceden a desprenderse de sus reliquias ni siquiera a cambio de dinero, los discos, los 
baúles, las fotos de Gardel en sus películas, en viaje, en compañía de las "Rubias de New York" que lo escuchan extasiadas, las partituras de tangos que en sus portadas anuncian haber sido estrenados en películas filmadas en Francia y los Estados Unidos, dan cuenta de una movilidad incesante y atestiguan su pertenencia al mundo. En la difusión y el éxito mundial de Gardel, personificación del tango, se encarna para los porteños la difusión y el éxito del tango, patrimonio cultural de la ciudad de Buenos Aires, en el mundo. Con su temprana y accidentada muerte en medio de una gira internacional Gardel no sólo es la encarnación sino también el mártir de esa gesta exitosa. Los porteños se lo agradecen contribuyendo a su inmortalidad de muchas más maneras y en muchas más ocasiones de las que he logrado mencionar aquí.

La sacralidad otorgada a Gardel, el carácter de ser ya sea milagroso, ya sea mágico, único, e indiscutible que los porteños le otorgan, es sólo un ejemplo de uno de los modos más extendidos en que los habitantes de Buenos Aires entienden lo que es su patrimonio, es decir, conciben aquello que es memorable, identifican aquello en lo que se reconocen como porteños y perciben aquello frente a lo cual experimentan sentimientos de pertenencia colectiva. Desde el Gauchito Gil al conjunto de los desaparecidos de la última dictadura, pasando por el Che Guevara y Perón; desde la Madre María a Evita, y desde Gardel a Maradona; una buena parte de lo que nuestra memoria local preserva y una buena parte de lo que convoca a amplios sectores de la población, se organiza en torno a personas reales a quienes se les asigna un valor extraordinario. Este desvío de lo que se considera memorable y sagrado hacia personas específicas vivas y muertas, problematiza la intangibilidad de lo patrimonializable, al afirmar su profundo enraizamiento en cuerpos humanos tangibles.

\section{Referencias}

ABALLE, Guadalupe. Tiempos de romance: la novia de Gardel. Todo es Historia, Buenos Aires, año 36, n. 431, p. 68-71, junio 2003.

ARCHETTI, Eduardo. Models of masculinity in the poetics of the Argentinian tango. In: ARCHETTI, Eduardo. Exploring the written: anthropology and the multiplicity of writing. Oslo: Scandinavian University Press, 1994. p. 97-123. 
ARCHETTI, Eduardo. El potrero, la pista y el ring: las patrias del deporte argentino. Buenos Aires: Fondo de Cultura Económica, 2001.

BERNARD, Carmen. Historia de Buenos Aires. Buenos Aires: Fondo de Cultura Económica, 1999.

BOURDIEU, Pierre. El sentido práctico. Madrid: Taurus, 1991.

CALAVIA SÁEZ, Oscar. Fantasmas falados: mitos e mortos no campo religioso brasileiro. Campinas: Editora da UNICAMP, 1996.

CARLINI, Sabrina. Iconografía de un mito: “cada día se ve mejor". Todo es Historia, Buenos Aires, año 36, n. 431, p. 7-16, junio 2003.

CAROZZI, María Julia. El reconocimiento de las formas populares y locales de la memoria en las políticas de patrimonio cultural. In: JORNADAS DE PATRIMONIO INTANGIBLE, 3., 2002, Buenos Aires. Terceras Jornadas de Patrimonio Intangible: el espacio cultural de los mitos, ritos, leyendas, celebraciones y devociones. Buenos Aires: Comisión para la Preservación del Patrimonio Cultural de la Ciudad de Buenos Aires. En prensa.

CHERTUDI, Susana; NEWBERY, Sara. La difunta Correa. Buenos Aires: Editorial Huemul, 1978.

CHUMBITA, Hugo. Jinetes rebeldes: historia del bandolerismo social en la Argentina. Buenos Aires: Vergara, 2000.

COLLIER, Simon. Carlos Gardel: su vida, su música, su época. Buenos Aires: Sudamericana, 1988.

COMISIÓN PARA LA PRESERVACIÓN DEL PATRIMONIO HISTÓRICO CULTURAL DE LA CIUDAD DE BUENOS AIRES. Primeras jornadas de patrimonio intangible: memorias, identidades e imaginarios sociales. Buenos Aires, 2001.

GOBELLO, José. Letras de Tango: selección 1897-1981. Buenos Aires: Centro Editor, 1997.

GROPPO, Ezequiel. Un aliento para la hinchada: Gardel y su pasión por el fútbol. Todo es Historia, Buenos Aires, año 36, n. 431, p. 72-74, junio 2003. JÁUREGUI, Andrea. La intimidad con la imagen en el Río de la Plata: de la visión edificante a la conformación de una conciencia estética. In: DEVOTO, Fernando; MADERO, Marta. Historia de la vida privada en la Argentina: país antiguo, de la colonia a 1870. Buenos Aires: Taurus, 1999. p. 248-273. 
JORNADAS DE PATRIMONIO INTANGIBLE, 3., 2002, Buenos Aires. Terceras Jornadas de Patrimonio Intangible: el espacio cultural de los mitos, ritos, leyendas, celebraciones y devociones. Buenos Aires: Comisión para la Preservación del Patrimonio Cultural de la Ciudad de Buenos Aires. En prensa.

LA MESA DEL CAFÉ [Foro]. Disponible en: <http://www.todotango.com.ar>. LACARRIEU, Mónica; PALLINI, Verónica. La gestión de patrimonio(s) intangible(s) en el contexto de políticas de la cultura. In: JORNADAS DE PATRIMONIO INTANGIBLE,1., 2000, Buenos Aires. Primeras Jornadas de Patrimonio Intangible: memorias, identidades e imaginarios sociales. Buenos Aires: Comisión para la Preservación del Patrimonio Histórico Cultural de la Ciudad de Buenos Aires, 2001. p. 81-104.

LE GOFF, Jacques. Lo maravilloso y lo cotidiano en el Occidente medieval. Barcelona: Gedisa, 2002.

MARTÍN, Alicia. Carlos Gardel en el mito. In: JORNADAS DE PATRIMONIO INTANGIBLE, 3, 2002, Buenos Aires. Terceras Jornadas de Patrimonio Intangible: el espacio cultural de los mitos, ritos, leyendas, celebraciones y devociones. Buenos Aires: Comisión para la Preservación del Patrimonio Cultural de la Ciudad de Buenos Aires. En prensa.

MARTÍN, Eloísa. En torno a la tumba de Gilda: fanáticos devotos de una cantante popular argentina. In: CONGRESO INTERNACIONAL DE AMERICANISTAS, 51., 2003, Santiago de Chile. 2003.

MATAMORO, Blas. La ciudad del tango. Buenos Aires: Galerna, 1969. MELLOR, Philip; SHILLING, Chris. Re-forming the body: religion, community and modernity. Londres: SAGE, 1997

OCHOA GAUTIER, Ana María. El patrimonio intangible en un mundo globalizado: ¿de qué memoria estamos hablando? In: JORNADAS DE PATRIMONIO INTANGIBLE,1., 2000, Buenos Aires. Primeras Jornadas de Patrimonio Intangible: memorias, identidades e imaginarios sociales Buenos Aires: Comisión para la Preservación del Patrimonio Histórico Cultural de la Ciudad de Buenos Aires, 2001. p. 11-18.

ORGAMBIDE, Pedro. Un tango para Gardel. Buenos Aires: Sudamericana, 2003. 
RODMAN, Gilbert. Elvis after Elvis: the posthumous career of a living legend. London: Routledge, 1996

RODRIGUES, José Carlos. O corpo na História. Rio de Janeiro: Editora Fiocruz, 1999.

SEMAN, Pablo. A "fragmentação do cosmos": um estudo sobre as sensibilidades de fiéis pentecostais e católicos de um bairro da Grande Buenos Aires. 2000. Tese (Doutorado em Antropologia Social)-PPGAS/UFRGS, Porto Alegre, 2000.

TAUSSIG, Michael. Mimesis and alterity: a particular history of the senses. London: Routledge, 1993.

TRESSERRAS, Jordi. Patrimonio Intangible y Turismo Cultural. In: JORNADAS DE PATRIMONIO INTANGIBLE,1., 2000, Buenos Aires. Primeras Jornadas de Patrimonio Intangible: memorias, identidades e imaginarios sociales. Buenos Aires: Comisión para la Preservación del Patrimonio Histórico Cultural de la Ciudad de Buenos Aires, 2001. p. 81-104. YÚDICE, George. Negociar el valor añadido del patrimonio intangible. In: JORNADAS DE PATRIMONIO INTANGIBLE,1., 2000, Buenos Aires. Primeras Jornadas de Patrimonio Intangible: memorias, identidades e imaginarios sociales. Buenos Aires: Comisión para la Preservación del Patrimonio Histórico Cultural de la Ciudad de Buenos Aires, 2001. p. 53-66.

Recebido em 27/07/2003 Aprovado em 20/08/2003 